JPCS

Peqguruang: Conference Series

Vol. 2 No. 2 Nov. 2020

eISSN: 2686-3472

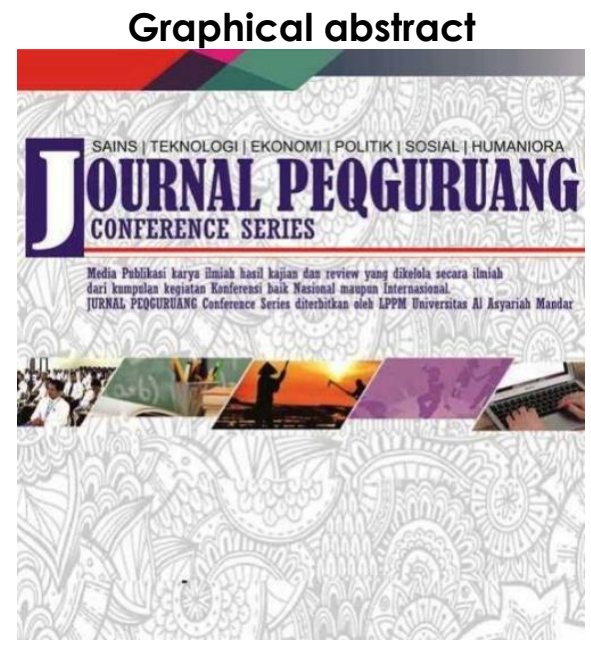

\title{
KONTRIBUSI PROGRAM PNPM MANDIRI PEDESAAN TERHADAP PENINGKATAN PENDAPATAN MASYARAKAT MISKIN DI DESA GALESO KECAMATAN WONOMULYO
}

\author{
${ }^{1 *}$ Nilam Cahya, ${ }^{2}$ Chuduriah Sahabuddin, ${ }^{3} \mathrm{Abdul}$ Latief \\ Program Studi PPKn Fakultas Keguruan dan Ilmu \\ Pendidikan Universitas Al Asyariah Mandar \\ *Corresponding author \\ 1nilang1997@gmail.com, \\ 22chuduriah.sahabuddin01@gmail.com. \\ 3latief2002@gmail.com
}

\begin{abstract}
the purpose of this study was to determine the level of effectiveness of the PNPM rural program, determine the impact before and after getting PNPM assistance and what kind of contribution PNPM made to the galeso village. the type of research is descriptive quantitative conducted to determine the level of effectiveness, the impact of PNPM and what contributions are made by PNPM. The population is 42 people. the data collection process was carried out with a questionnaire to calculate how much the effectiveness of the PNPM program, the impact caused by the presence of PNPM related to community income and PNPM contributions. the data collected was analyzed using a Likert scale by giving scores to the questionnaire then interpreted in the form of narration. this is pointed out in terms of the level of achievement of the objectives running very effectively with an answer score of $80.66 \%$, in terms of integration running effectively with an answer score of $76.71 \%$ dam in terms of adaptation running very effectively with an answer score of $82.17 \%$. to look for an impact on income levels before the dam after borrowing PNPM funds, namely by using SPSS.
\end{abstract}

Keywords: Contribution, Community Empowerment, Landing
Abstrak

Tujuan dari penelitian ialah untuk mengetahui tingkat efektivitas program PNPM Mandiri Pedesaan, mengetahui dampak sebelum dan sesudah mendapatkan bantuan PNPM dan seperti apa kontribusi yang diberikan PNPM untuk desa galeso. Jenis penelitian yaitu Kuantitatif deskriptif yang dilakukan untuk mengetahui tingkat efektivitas, dampak dari PNPM dan kontribusi apa yang telah diberikan oleh PNPM. Populasi berjumlah 42 orang. Proses pengambilan data dilakukan dengan lembaran angket untuk dihitung seberapa besar tingkat efektivitas program PNPM, dampak yang ditimbulkan dengan adanya PNPM berkaitan dengan pendapatan masyarakat dan kontribusi PNPM. Data yang terkumpul dianalisa dengan menggunakan skala Likert dengan memberikan skor pada kuisioner kemudian di interpretasikan dalam bentuk narasi. Hal ini ditunjuk dalam hal tingkat pencapaian tujuan berjalan sangat efektif dennga skor jawaban sebesar $80.66 \%$, dalam hal integrasi berjalan dengan efektif dengan skor jawaban $76.71 \%$ dan dalam hal adaptasi berjalan dengan sangat efekti dengan skor jawaban $82,17 \%$. Untuk mencari dampak terhadap tingkat pendapatan sebelum dan sesudah meminjam dan PNPM yaitu dengan menggunakan SPSS.

Kata Kunci: Kontribusi; Pemberdayaan Masayarakat; Pendapatan.

\section{Article history \\ DOI: http://dx.doi.org/10.35329/ip.v2i2.1614 \\ Received : 11 September 2020 | Received in revised form : 21 September 2020 | Accepted :09 Oktober 2020}




\section{PENDAHULUAN}

Permasalahan kemiskinan yang cukup kompleks membutuhkan intervensi semua pihak secara bersama dan terkoordinasi. Namun penanganannya selama ini cenderung parsial dan tidak berkelanjutan. Peran dunia usha dan masyarakat pada umumnya juga belum optimal. Kerelawanan sosial dalam kehidupan masyarakat yang dapat menjadi sumber penting pemberdayaan dan pemecahan akar permasalahan kemiskinan juga mulai pudar. Untuk itu diperlukan perubahan yang bersifat sistemik dan menyeluruh dalam upaya penanggulangan kemiskinan (Sari 2011: 58).

Bedasarkan data jumlah penduduk. Dari jumlah tersebut persentase penduduk miskin didesa mencapa 12,85 persen sementara dikota sebesar 6,89 peesen. Sementara itu pada bulan maret 2018, jumlah penduduk miskin (penduduk dengan pengeluaran perkapita perbulan dibawah garis kemiskinan) di sulawesi barat mencapai 151,78 ribu orang (11,25 persen), meningkat sebesar 2,3 ribu orang dibandingkan dengan kondisi september 2017 yang sebesar 149,47 ribu orang $(11,18$ persen) (Badan Pusat Statistik: 2018).

Merebaknya kemiskinan antara lain adalah akibat dari minimnya sumber daya dan tidak produktifitasnya kaum perempuan. Sehingga sangat urgen untuk diorientasikan pada peningkatan pendapatan bagi kaum perempuan. (Latief, A., Maryam, S., \& Yusuf, M, 2019: 165).

Pada pemberdayaan pendekatan proses lebih memungkinkan pelaksanaan pembangunan yang memanusiakan manusia. Dalam pandangan ini pelibatan masyarakat dalam pembangunan lebih mengarah kepada bentuk partisipasi, bukan dalam bentuk mobilisasi. Partisipasi perumusan program membuat masyarakat tidak semata-mata berkedudukn sebagai konsumen program, tetapi juga sebagai produsen karena telah ikut serta terlibat dalam proses pembuatan dan perumusannya, sehingga masyarakat merasa ikut memiliki program tersebut dan mempunyai tanggung jawab bagi keberhasilannya serta memiliki motivasi yang lebih bagi partisipasi tahap-tahap berikutnya (Matdoan 2015).

Berdasarkan konsep PNPM yang menyelenggarakan program penanggulangan kemiskinan melalui kegiatan yang berbasis masyarakat itu sendiri, maka diharapkan kelompok masyarakat marginal mampu mengurangi ketertinggalan yang ada dengan adanya pengetahua dan keterampilan. Konsep PNPM merupakan konsep yang sangat menyentuh masyarakat untuk mencari akar permasalahan, namun pada realitanya belum banyak masyarakat yang tahu tentang program PNPM itu sendiri (Muazansyah, 2010).

Salah satu kegiatan untuk meningkatkan taraf hidup masyarakat adalah melakukan pemberdayaan terhadap mereka yaitu dalam bentuk bantuan dana yang bertujuan agar mereka bisa berusaha dengan baik serta membuka lapangan pekerjaan baru. Sasaran utama penyelenggaraan pinjaman dana bergulir dari PNPM Mandiri pedesaan dilaksanakan untu mendukung masyarakat golongan menengah kebawah pada sektor pertanian, perindustrian, berkelompok maupun bandan usaha. Sehingga diharapkan terjadi peningkatan kesejateraan para masyarakat yang melalui pinjaman dana bergulir PNPM Mandiri Pedesaan (Hasanuddin, 2015).

Salah satu upaya yang dilakukan oleh berbagai pihak tersebut adalah dengan jalan pemberdayaan masyarakat. Pemberdayaan masyarakat menjadi concern publik dan dinilai sebagai sala satu pendekatan yang sesuai dalam mengatasi masalah sosial, terutama kemiskinan yang dilaksanakan sebagai elemen mulai dari pemerintah, dunia usaha dan masyarakat melalui organisasi masyarakat sipil (Hadi, 2015).

\section{METODE PENELITIAN}

\section{Jenis Penelitian}

Penelitian ini menggunakan jenis penelitian Analisis Dekriptif dengan pendekatan kuantitatif penelitian deskriptif merupakan penelitian yang berusaha mendeskripsikan suatu gejala, peristiwa dan kejadian yang terjadi pada masa sekarang dimana peneliti berusaha memotret peristiwa dan kejadian yang menjadi pusat perhatian untuk kemudian digambarkan sebagaimana adanya.

Sedangkan yang dimaksud dengan pendekatan kuantitatif adalah pendekatan yang digunakan dalam penelitian dengan cara mengukur indikator-indikator variabel penelitian sehingga diperoleh gambaran diantara variabel-variabel tersebut (Soemantri, 2015).

\section{Lokasi dan Waktu Penelitian}

Penelitian ini deilakukan di Desa Galeso Kec. Wonomulyo Kab. Polewali Mandar. Dan penelitian ini dilaksanakan selama awal bulan februari sampai bulan juli 2020.

\section{Populasi dan Sampel}

1. Populasi Penelitian

Populasi adalah wilayah generalisasi yang terdiri atas obje/subjek yang mempunyai kualitas dan karakteristik tertentu yang ditetapkan oleh peneliti untuk dipelajari dan kemudian ditarik kesimpulannya.

Adapun populasi dalam penelitian ini ialah kelompok PNPM yakni Simpan Pinjam Perempuan (SPP) di Desa Galeso. Jumlah Kelompok yakni 4 kelompok.

2. Sampel Penelitian

Dalam pengambilan sampel peneliti menggunakan tehknik sampling purposive. Menurut Arikunto (2011) sampling bertujuan (purposive sampling) yaiu teknik sampling yang digunakan peneliti dengan pertimbangan-pertimbangan tertentu dalam pengmabilan sampel. Maka sampel dalam penelitian ini ialah sebanyak 42 orang. 


\section{Metode Pengumpulan Data}

\section{a. Data Primer}

Data primer merupakan data yang didapat dari sumber pertama baik individual atau perorangan. Dalam penelitian ini data primer diperoleh secara langsung dari wawancara kepada masyarakat miskin yang mendapat bantuan di Desa Galeso Kecamatan Wonomulyo, Kabupaten Polewali Mandar denganb menggunakan daftar pertanyaan (kuisioner) yang telah disiapkan.

b. Data Sekunder

Data sekunder adalah data yang diperoleh secara tidak langsung, yaitu diambil dari literatur-literatur yang ada hubungannya denga masalah yang diteliti, misalnya pada buku acuan, majalah dan struktur organisasi.

\section{Teknik Pengumpulan Data}

\section{Observasi}

Observasi atau pengamatan langsung yang dilakukan dilokasi penelitian. Hal ini dapat digunakan untuk mengetahui kegiatan dalam program PNPM Mandiri berkaitan dengan program kelompok perempuan.

\section{Wawancara}

Wawancara yang digunakan adalah wawancara terstruktur dan wawancara tidak terstruktur. Wawancara terstruktur dilakukan dalam penelitian ini mengacu pada pedoman wawancara yang penulis susun rumusan permasalahan yang diberikan. Sedangkan wawancara tidak terstruktur yang dilakukan dalam penelitian ini adalah wawancara tidak sah yang tidak terlalu, mengacu pada pedoman wawancara.

3. Dokumentasi

Dokumentasi adalah mengambil foto aktivitas yang dilakukan oleh kelompok dalam program PNPM Mandiri.

\section{Metode Analisis Data}

Untuk menguji rumusan masalah pertama menggunakan skala likert dengan meberikan skor pada kuisioner kemudian di interpretasikan dalam bentuk narasi. Skala likert digunakan untuk mengukur sikap, pendapat dan persepsi seseorang atau sekelompok orang tentang fenomena social.

Dengan skala likert, maka variabel yang akan diukur dijabarkan menjadi indikator tersebut dijadikan sebagai titik tolak ukur untuk menyusun item-item instrumen yang dapat berupa pertanyaan atau pernyataan. Jawaban setiap item instrumen menggunakan gradasi sangat positif sampai sangat negatif dengan skor dari setiap indikator sebagai berikut:

$\begin{array}{ll}\text { Sangat Setuju (SS) } & =5 \\ \text { Setuju (S) } & =4 \\ \text { Ragu - ragu (RG) } & =3 \\ \text { Tidak Setuju (TS) } & =2 \\ \text { Sangat Tidak Setuju (STS) } & =1\end{array}$

Interpretasi Skor Perhitungan

Agar mendapatkan hasil interpretasi, terlebuh dahulu harus diketahui nilai skor tertinggi (maksimal), indeks skor dan interval skor.

1. Menghitung skor tertinggi

Skor Maksimal = Jumlah Responden $\mathrm{x}$ Skor

Tertinggi Likert x Jumlah Pertanyaan

2. Menghitung Indeks Skor

Indeks Skor $(\%)=\frac{\text { total Skor }}{\text { Skor Maksimal }} \times 100$

3. Rumus Interval

$$
\mathbf{I}=\frac{100}{\text { Jumlah Skor Liker }}
$$

\section{HASIL DAN PEMBAHASAN}

Untuk menguji Rumusan masalah pertama menggunakan skala Likert dengan cara meberikan skor pada jawaban responden kemudian untuk menguji apakah instrumen yang digunakan terukur atau tidak maka digunakan uji Validitas dan Reliabilitas. Untuk menguji rumusan masalah kedua menggunakan uji statistik parametrik yaitu uji beda rata-rata (dua sampel berkolerasi). Dan untuk rumuan masalah ketiga menggunakan tehknik analisis deskriptif.

Tabel 1. Interval skor jawaban likert

Indeks Skor

\section{Keterangan}

$\begin{array}{ll}0 \%-19,99 \% & \text { Sangat Tidak Efektif } \\ 20 \%-39,99 \% & \text { Tidak Efektif } \\ 40 \%-59,99 \% & \text { Cukup Efektif } \\ 60 \%-79,99 \% & \text { Efektif } \\ 80 \%-100 \% & \text { Sangat Efektif }\end{array}$

1. Uji Tingkat Efektivitas Program PNPM Mandiri Pedesaan

a. Pencapaian Tujuan

Dari jawaban seluruh responden, maka dapat dilihat indeks skor jawaban yang di dapat dari tolak ukur Pencapaian Tujuan yaitu :

$$
\begin{aligned}
& \text { 1. Total Skor }=1694 \\
& \text { 2. Skor maksimal } \quad=2100 \\
& \text { 3. Indeks Skor }=\frac{\text { Total Skor }}{\text { Skor Maksimal }} \times 100 \% \\
& =\frac{1610}{2100} \times 100 \% \\
& =80.66 \%
\end{aligned}
$$

Jadi dapat disimpulkan bahwa PNPM di Daerah penelitian berjalan sangat efektif.

b. Integrasi 
Dari jawaban seluruh responden, maka dapat dilihat indeks skor jawaban yang di dapat dari tolak ukur integrasi yaitu:

$$
\begin{array}{ll}
\text { 1. Total Skor } & =1611 \\
\text { 2. Skor maksimal } & =2100 \\
\text { 3. Indeks Skor } & =\frac{\text { Total Skor }}{\text { Skor Maksimal }} \times 100 \% \\
& =\frac{1611}{2100} \times 100 \% \\
& =76,71 \%
\end{array}
$$

Dari jawaban diatas dapat dismpulkan bahwa PNPM didaerah penelitian berjalan efektif.

c. Adaptasi

Dari jawaban seluruh responden, maka dapat dilihat indeks skor jawaban yang di dapat dari tolak ukur Adaptasi yaitu :

$$
\begin{aligned}
& \text { 1. } \text { Total Skor }=1694 \\
& \text { 2. Skor maksimal } \quad=2100 \\
& \text { 3. Indeks Skor } \quad=\frac{\text { Total Skor }}{\text { Skor Maksimal }} \times 100 \% \\
& =\frac{1610}{2100} \times 100 \% \\
& =80.66 \%
\end{aligned}
$$

\begin{tabular}{|c|c|c|c|c|c|}
\hline & & Mean & $\mathrm{N}$ & $\begin{array}{c}\text { Std. } \\
\text { Deviation }\end{array}$ & $\begin{array}{l}\text { Std. Error } \\
\text { Mean }\end{array}$ \\
\hline & sebelum & 456428 & 42 & 2996650,27 & 462393,17665 \\
\hline & penerimaa & 5,7143 & & 856 & \\
\hline 1 & sesudah & 803809 & 42 & 4751479,99 & 733169,28041 \\
\hline & $\begin{array}{l}\text { penerimaa } \\
\mathrm{n}\end{array}$ & 5,2381 & & 439 & \\
\hline
\end{tabular}

\begin{tabular}{|c|c|c|c|c|}
\hline \multicolumn{5}{|c|}{ Paired Samples Correlations } \\
\hline & & $\mathrm{N}$ & Correlation & Sig. \\
\hline \multirow{4}{*}{$\begin{array}{l}\text { Pair } \\
1\end{array}$} & sebelum & 42 & ,937 &, 000 \\
\hline & penerimaan \& & & & \\
\hline & sesudah & & & \\
\hline & penerimaan & & & \\
\hline
\end{tabular}

Dari jawaban diatas dapat disimpulkan bahwa PNPM di daerah penelitian berjalan dengan sangat efektif.

2. Dampak setelah adanya PNPM

\section{Paired Samples Statistics}

Sumber: Data Primer (diolah)

Dari tabel Paired Sample Statistik dapat dilihat bahwa penelitian ini berjumlah 42 responden.

Sumber: Data Primer (diolah)

Berdasarkan tabel diatas dapat disimpulkan bahwa ada perbedaan tingkat pendapatan sebelum dan sesudah meminjma PNPM. Hal ini menunjukkan kekuatan hubungan yang menyebabkan pendapatan sebelum dan sesudah berbeda nyata. Pendapatan setelah mendapat pinjaman PNPM lebih besar dibandingkan pendapatan sebelumnya.

3. Kontribusi PNPM Mandiri Pedesaan
Dengan adanya bantuan langsung PNPM Mandiri masyarakat sangat terbantu dalam memperbaiki perekonomian keluarga. Setiap masyarakat yang meminjam dana bantuan PNPM secara sukarela meminjam bantuan tersebut tanpa paksaan dari siapapun. Dana yang diberikan juga sesuai dengan kebutuhan yang diperlukan setiap peminjamnya. Dalam pencairan dana bagi kelompok yang engikuti ketentuan yang diberikan PNPM maka tidak ada masalah yang dihadapi.

\section{KESIMPULAN}

Dari hasil penelitian dan pembahasan yang telah diuraikan diatas maka penulis dapat menyimpulkan bahwa :

1. penelitian dari tolak ukur pencapaian tujuan (X1) berjalan sangat efektif dengan indeks skor jawaban yakni sebesar 80,66 \%, dari Tolak Ukur Integrasi (X2) berjalan efektif dengan indeks skor jawaban yakni sebesar 76,71 \%, serta dari tolak ukur Adaptasi (Y) berjalan sangat efektif dengan indeks skor jawaban yakni sebesar $82,17 \%$.

2. Berdasarkan nilai signifikan hasil uji menunjukkan bahwa nilai korelasi antara dua variabel adalah 0,937 dengan sig sebesar 0,000. Hal ini menunjukkan kekuatan hubungan antara dua rata - rata pendapatan sebelum dan sesudah adalah signifikan berbeda nyata dengan tingkat kepercayaan 95\%. Sehingga PNPM menberikan dampak positif terhadap pendapatan masyarakat.

3. Dalam pelaksanaan PNPM masalah yang sering terjadi yaitu keredit macet dan jangka waktu pengembalian setiap bulannya tidak sesuai dengan ketentuan yang ditetapkan.

\section{DAFTAR PUSTAKA}

Arikunto Suharsimi. (2011). Prosedur penelitian suatu pendekatan praktik (edisi revisi VI). Jakarta: Rineka Cipta.

Data Badan Pusat Statistik sulawesi Barat tahun 2018.

Hadi, Purbathin, Agus. (2015). Konsep pemberdayaan, partisipasi dan kelembagaan dalam pembangunan.

Hasanuddin, Tubagus. (2013). Peranan Kader Pemberdayaan Masyarakat Dsa (KPMD) dan partisipasi masyarakat masyarakat Pada Program Nasional Pemberdayaan Masyarakat Mandiri Pedesaan (PNPMMP). Vol 1 No 1 Januari 2013.

Muazansyah. (2010). Konsep pemberdayaan, partisipasi dan kelembagaan dalam pembangunan. 
Matdoan, Usman. (2015). Peranan Program PNPM

Mandiri Pedesaan dalam mendorong partisipasi dan peberdayaan masyarakat local.

Latief, A., Maryam, S., \& Yusuf, M. (2019). Kesetaraan Gender dalam Budaya Sibaliparri Masyarakat Mandar. Pepatudzu: Media Pendidikan dan Sosial Kemasyarakatan, 15(2), 160-173.

Sari, Dian, Novita. (2011). Analisis Program PNPM Terhadap Peningkatan Pendapatan Masyarakat Miskin di Kecamatan Andong. Skripsi Boyolali: Univesitas Sebelas Maret Surakarta. Vol. 2. No .4 hal:5-8

Soemantri, Rusliwa, Gumilar. (2015). Memahami metode Penelitian Kuantitatif Vol 9, No. 2. Desember 2015. 